\title{
Improvement through inspection? The development of the new Commission for Health Improvement in England and Wales
}

\author{
Kieran Walshe
}

\section{Introduction}

Inspection and external review are increasingly used in healthcare systems throughout the world, in various forms, in pursuit of quality assurance and improvement. Although the experience of systems such as accreditation in those countries which have used them for decades is decidedly mixed, ${ }^{1}$ we are nevertheless witnessing what has been described as an explosion ${ }^{2}$ in external audit, regulation, review, and inspection-not just in health care, but across the public and private sector. But little evidence exists to show that regulation and inspection improve quality, and some would argue that they conflict with a modern understanding of effective quality improvement. ${ }^{\text {1a }}$ This article explores the contribution that external review and inspection can make to quality improvement in the context of the National Health Service (NHS) in England and Wales, where a new national statutory healthcare inspectorate is about to be established.

\section{A new agency for external review and inspection in health care in England and Wales}

The British government is currently implementing a range of reforms to the NHS in England designed to make the quality of health care central to policy and practice. ${ }^{3}$ It can be argued that those reforms, spelt out in some detail in A First Class Service: Quality in the New $N H S^{4}$ and described in box 1 , represent the most radical and far reaching effort in the history of the NHS to put systems for healthcare quality assurance and improvement in place. Although they present an ambitious agenda for implementation, ${ }^{5}$ they have been widely welcomed by professional bodies, managers, and health authorities and healthcare providers. ${ }^{6}$

The reforms will create a new, independent statutory body called the Commission for Health Improvement, reporting directly to the Secretary of State for Health and tasked with "offer[ing] an independent guarantee that local systems to monitor, assure, and improve clinical quality are in place". ${ }^{4}$ Its core functions will include national leadership on clinical governance; scrutinising local arrangements for clinical governance through a rolling programme of local reviews of NHS providers; undertaking service reviews to monitor the implementation of national guidance; helping the NHS to tackle serious or persistent clinical problems; and overseeing and assisting with external incident inquiries. Box 2 sets out the legal framework for the operation of the new commission. Although other statutory and non-statutory forms of external review or
The reforms create new arrangements for setting standards of care (through a $\mathrm{Na}-$ tional Institute for Clinical Excellence, and the development of national service frameworks); delivering those standards (through local arrangements for clinical governance ${ }^{9} 10$ ); and monitoring the quality of care and systems for quality improvement (through performance measures, and a new Commission for Health Improvement).

The quality reforms are being enacted at a time when public confidence in the healthcare system and especially in the healthcare professions has been seriously undermined by several high profile quality failures in areas such as paediatric cardiac surgery and cervical screening ${ }^{11}$ which seem to call into question the ability of the healthcare system and the professions to assure the quality of care. As a result, there is media and public pressure for more robust systems for quality assurance and improvement, ${ }^{12}$ and less professional resistance to having such formal and explicit systems than there has been in the past. ${ }^{13}$ In other words, there is now a window of opportunity for radical reform. Indeed, in parallel with the government's quality reforms, other changes are also taking place, most notably the decision by the General Medical Council to develop a system of revalidation in which all doctors will be required as a condition of their continuing registration to produce evidence to show that their standard of practice is being monitored and is acceptable. The government's reforms should also be seen in the context of its wider policy agenda for public services, which emphasises greater accountability through inspection and review, extensive performance measurement and management, incentives and rewards for excellence, and nationally set standards of provision, but tempers them with considerable pragmatism and flexibility about structures and approaches to service delivery. ${ }^{14}$

Box 1 Background to the quality reforms to the British NHS

inspection have been used in parts of the British NHS in the past, this is the first time that an agency with such a broad remit for quality improvement has been created.

The commission's primary purpose, as its title suggests, is to facilitate and promote improvements in the quality of healthcare in the NHS in England and Wales. However, the reality of its objectives may be more complex. It will need to respond to public and political 
The Health Act sets out the structure of the new commission: a non-executive chair, a chief executive to be titled the Director of Health Improvement, and a board of non-executive directors or commissioners. It also provides the commission with a wide range of powers. For example, it will have statutory rights of entry to NHS premises, and rights of access to individuals and to all data sources. It will have qualified immunity from legal action for libel arising from anything it publishes, and will even be able in some circumstances to override the usual duties of patient confidentiality if this is necessary in the investigation of a quality problem.

It is also interesting to note, however, what powers the commission does not possess. Most obviously, it has no sanctions or incentives which it can use to force healthcare organisations to take note of its views, apart from the publication of its reports. It can only advise the Secretary of State for Health if it thinks actions such as changes in organisational configuration or leadership are needed, and it is up to the Secretary of State to decide what action to take. In addition, the commission's powers are limited to NHS organisations and property, and exclude healthcare providers in the private sector and most general practice premises (which are usually owned by the GPs themselves, not the NHS). Significantly, although the independence of the commission has been much emphasised by the government, ${ }^{2}$ the Health Act effectively gives the Secretary of State complete powers to direct what it does to exercise any of its functions.

The Health Act offers few clues to how the commission will actually behave, and no details of what it will do to fulfil the remit set out above. It is an example of what has been termed "emergent" policy making, ${ }^{15}$ in which the principles of the proposals are set out while the practical reality and the detail of implementation are allowed to evolve slowly through consultation and progressive revision.

The appointment of the first chair and chief executive of the Commission for Health Improvement is already underway. It is planned that the commission will come into being in autumn 1999, and that it will be ready for its first full year of work in April 2000 .

Box 2 The legal framework for the Commission for Health Improvement demands for assurance that patients are protected from poor performance and for information about the quality of care of different healthcare providers. At the same time, it will need to develop a constructive relationship with those providers based on mutual respect and partnership to promote change and improvement. It will also have to establish ways of working with various existing organisations concerned with improving the quality of health care, including the professional bodies. It will need to balance the different demands of its responsibilities for reviewing healthcare organisations, investigating major problems or inquiries, and providing leadership for quality improvement in health care.

The commission will be, in effect, a new national health services inspectorate, though policy makers have tended to avoid describing its function as inspection, preferring terms such as review or scrutiny. This article explores the likely role and remit of the Commission for Health Improvement, and discusses the use of external review or inspection in the NHS in England and Wales; how external review and inspection fit into our understanding of effective quality improvement; the review or inspection process itself; and the publication and dissemination of review findings.

\section{The commission and other healthcare inspectorates in England}

The new commission is far from being the first or only external review or inspection body working in health care in the UK (table 1). Various other organisations are involved in reviewing the quality of health care. Some have a statutory role, established by legislation, and their reviews are mandatory for the organisations they inspect (such as the National Audit Office and the Audit Commission). Others have what could be termed a semi-statutory status, in that although their inspections have no legal force, there are strong incentives for organisations to submit themselves to the process. For example, the medical royal colleges inspect healthcare providers to assess their suitability as providers of training for junior medical staff, but because those organisations need junior medical staff to sustain their services they have little option but to submit to and work through the inspection process. A third group is entirely non-statutory, and healthcare organisations participate of their own free will. Examples would be the accreditation programmes established by the King's Fund and the Hospital Accreditation Programme.

In recent years in the NHS there has been a marked shift from systems of inspection that are non-statutory and voluntary towards sys-

Table 1 Existing external review and inspection bodies working in the NHS in England

\begin{tabular}{lll}
\hline Statutory & Semi-statutory & Non-statutory \\
\hline Audit Commission & Clinical Negligence Scheme for Trusts & Hospital Accreditation Programme \\
Health Advisory Service & Medical royal colleges & King's Fund health quality service \\
National Audit Office & Calman-Hine cancer accreditation scheme & Confidential enquiries \\
Mental Health Act Commission & & Clinical Pathology Accreditation \\
& & (CPA) \\
& & Investors in People (IIP) \\
& Chartermark \\
\hline
\end{tabular}


tems which are statutory and mandatory. For example, participation in the Clinical Pathology Accreditation (CPA) programme has become mandatory for laboratories which undertake cervical screening, and policy documents make it clear that participation by doctors in the Confidential Enquiries, once voluntary, will in future be required. The new Commission for Health Improvement clearly belongs in the first column of table 1, and strengthens the statutory mechanisms for review and inspection considerably.

Table 1 raises two important questions. Firstly, where does the new commission fit into the existing complex picture of external review or inspection? And, secondly, what can the commission learn from the experience of current inspection bodies as it develops its own process for external review.

The fragmented and already complicated systems of review and inspection already in place mean that finding the right place and focus for the new commission's activities requires care and sensitivity. For example, the new commission could plan and undertake its activities in partnership with existing inspection bodies to make sure that unnecessary overlap or burden on the inspected organisations is minimised. More imaginatively, the commission could act to bring together the existing systems for inspection and their results, so that it would become a centre for the collation and exchange of information from a range of existing inspection bodies. It would then not just be contributing to those systems but leading and coordinating their work, and setting an overall framework for inspection and external review.

If the commission pays little or no attention to the existing inspection infrastructure in the NHS, it is likely that whatever systems for inspection or review it puts in place will duplicate what is already there, resulting in wasted time and effort for all involved. Moreover, it is inevitable that inconsistencies and contradictions between the standards and processes used by different inspection bodies will emerge, resulting in confusion and detracting from the purpose of the whole process. It has been observed that healthcare providers already suffer from "inspection fatigue" when visited in close succession by several of the bodies listed in table 1. Each may have the best of intentions, but taken together they can impose an undue burden on the organisation. Simply adding the commission to the long current list of inspection bodies may exacerbate that problem if these issues are not tackled.

Although the commission could learn much from the experience of the existing review and inspection bodies in health care, both in the UK and elsewhere, there is relatively little organised empirical research on which to draw, and no obvious model of effectiveness to follow. However, some practical realities are already clear. For example, the credibility of the new commission will need to be established early and maintained. It cannot afford to leave itself open to criticism of its methods or staff, which could dent public and professional con- fidence in its work, and its reviews need to be demonstrably rigorous, objective, and transparent from the start. The commission could usefully aim to be a role model in quality improvement, demonstrating by its own conduct the importance of quality and the use of quality improvement to the NHS organisations it inspects. Pragmatically, it is important that the commission balances the demands of its different customers-most obviously the Department of Health and the Secretary of State to whom it reports; the healthcare provider organisations which it reviews or inspects; and the patients and the wider public who fund it through taxation. It cannot afford to be seen as the agent of any particular set of interests, and it may need to guard its independence carefully.

\section{Inspection and the philosophy of continuous quality improvement}

The process of external review and inspection proposed for the new commission does not sit easily for two reasons with the ideas of continuous quality improvement which have become dominant in quality thinking in many industries and which have been increasingly influential in health care. ${ }^{7}$

The first problem is the external nature of the inspection process. Quality improvement is an organisational challenge-internal to the healthcare provider-and systems for quality improvement are shaped by the organisation's structure and culture. Although an external perspective on performance and quality can be valuable, it cannot change anything. To bring about improvements, the organisation has to take on board the need for change and have the skills and resources itself to make change happen. External inspection processes can easily appear alien, unfamiliar, and threatening, producing an abreaction of defensiveness and self justification which makes improvement difficult to achieve.

The externality of inspection will need to be addressed both by the new commission and by the healthcare organisations it reviews. The commission could make its reviews less externalised, by incorporating data from local clinical governance systems and processes into the review, using assessor teams who are known to and respected by the organisation, and making the process of inspection transparent, formative, and open to discussion and revision. Similarly, the healthcare organisations that the commission reviews could make the review process serve their own internal quality improvement programme objectives. The inevitable preparation and self assessment that will precede the review, the process of review itself, and the subsequent feedback on performance all need to be tied into the organisations' own quality improvement processes, and not done simply to satisfy the commission. In short, the commission's reviews need to be seen as a joint endeavour in which both the commission and the organisation participate, learn, and improve as partners, rather than as something that one "does" to the other. 
The second problem is that inspection tells organisations what problems exist, but does not help them to solve those problems. To use a medical simile, inspection provides us with a description of the symptoms and, at best, a diagnosis. But it stops there; it does not go on to offer further investigations aimed at refining the diagnosis or, even more importantly, effective treatments capable of dealing with problems and improving health outcomes. Inspectorates such as the new Commission for Health Improvement often are neither resourced nor equipped with the skills in facilitation and organisational change which are needed to move beyond diagnosing quality problems to treating them. Indeed, it can be argued that this is not the function of the commission, but of the healthcare organisation itself and the wider NHS. It is important, however, that the new commission is clear about where its remit starts and finishes, and whether support and facilitation are part of the services it provides. If they are not, then there should be a pathway beyond inspection, through which that kind of support can be provided. Otherwise, the commission may identify problems but little may change as a result.

The context in which the commission must operate may make it difficult for it to put the philosophy of continuous quality improvement into practice. Firstly, the political climate could be argued to be antipathetic, with an emphasis on finding "failing" organisations and individuals and dealing with them in a robust and sometimes punitive way. This is a gross oversimplification and misrepresentation of the complex reality of quality improvement, in which no organisation is ever wholly failing, individual practice often reflects organisational norms or systems over which the individual has little control, and punitive measures breed fear and secrecy and do not result in improvement. But it may mean the commission is pressured to behave in these ways, to the detriment of its mission of improvement.

Secondly, the commission has an explicit remit to deal with persistent problems of poor performance (alongside other agencies such as those regulating the professions), and to undertake or support external inquiries into serious quality failures. These problems, though rare numerically, are enormously important symbolically, and they generate extensive media and political interest. It may be difficult for the commission to prevent this relatively small part of its overall agenda taking up more and more time and other resources, and driving out other important functions which are more likely to result in improvement. There is a risk that dealing with the outliers of performance may taint the commission's approach to dealing with the organisational mainstream.

\section{Review process}

The process by which the commission reviews "local systems to monitor, assure and improve clinical quality" ${ }^{4}$ lies at the heart of its remit, and will undoubtedly shape stakeholders' views of its performance and effectiveness. But designing a review process which meets the commission's objectives and also satisfies the needs of healthcare organisations, the public, and other stakeholders will not be straightforward.

First and foremost, the commission needs to decide whether its task is to review directly the quality of health care, or to review the quality and effectiveness of systems that organisations have in place to assure and improve qualitywhat might be called "meta-quality". The Health Act enables the commission to do both, but they are very different tasks. If the commission is to review directly the quality of health care in large and complex provider organisations, then its task becomes complex-perhaps unsustainably so. The experience of accreditation systems in other countries suggests that large and detailed sets of standards or measures for each service or care area are needed to structure the assessment process, and that measurement must involve the collection of considerable volumes of data. If, on the other hand, the commission focuses its attention on meta-quality - the effectiveness of systems for quality improvement in the organisations it is reviewing - then its task becomes both more clearly bounded and more achievable. The measurement and assessment process is still challenging, but it is manageable. It can be argued that a focus on meta-quality is more likely to bring about improvements, especially in the medium and long term. However, it is unlikely that the public and politicians will be satisfied by commission reports which say nothing about the actual quality of care, and focus instead on systems and processes for quality improvement. The commission may need to find ways to do both-focusing on systems for quality improvement, but also using a limited set of direct quality of care measures as well, perhaps in selected areas or clinical topics.

The commission will have finite resources for its reviews and inspections and will want to deploy them imaginatively in ways that will yield the greatest improvement. A universal programme of reviews of all healthcare providers is likely to waste resources on many reviews of organisations where few significant quality problems exist. By targeting its review on organisations where a range of data sources (such as previous commission visit reports, data from other inspection bodies, data from the organisation's own clinical governance systems, routine activity data, etc) suggest there are problems, the commission could make much more efficient use of its resources. By focusing its review of an organisation on particular service areas or directorates, again by using existing data to help to identify potential problems, the commission could again make better use of its resources. Overall, the commission's review process needs to work on the principle of proportionality, investing review resources in proportion to the scale of the organisation or service being reviewed and the quality improvements that are likely to result from the review.

It has already been observed that the credibility of the commission's review process will be crucial to the way that its reports are 
received and acted on by healthcare organisations and others. Although the commission will have undoubted authority because of its position and powers, it will still need to command the respect and support of the organisations which it inspects and of the wider public it serves. For the review process to be credible with healthcare organisations, it needs to be methodologically sound and to be implemented by assessors who are adequately trained and resourced. Methodologically, a need exists for scientific rigour and objectivity in the way that measures or standards used in the review process are developed. It would be unhelpful if they appeared to be based on personal opinion or precedent, conflicted with evidence from other sources, or took insufficient account of the local service context. Moreover, the way that measures or standards have been devised and the evidence on which they draw need to be transparent, so that the methods can be understood and challenged if necessary by others. To be credible in the eyes of patients, users, and the wider public, the commission's standards need to reflect public concerns about quality, which may not always match the priorities and values of the health professions.

However, even the most rigorous and robust review process is of little value unless those who act as assessors have the skills to use it properly. The credibility of the assessors used or employed by the commission will depend on their ability to understand and bring value to the organisations they review. If they are perceived as out of date in their own knowledge, lacking relevant experience of healthcare provision, or not having the interpersonal and facilitative skills required to be an effective assessor, the process itself will be brought into disrepute. Assessors also need to have a shared set of values and understanding of the purpose of the review process, and both careful selection and proper training will be needed. It seems that at least some assessors should be drawn from among practising clinicians and managers working in healthcare provider organisations, and that assessors should be trained and selected to ensure they have the skills and experience needed for the task. Some assessors even could be drawn from within the organisation to be inspected, which could reduce the problems of externality discussed earlier. Maintaining the quality and consistency of the review or inspection process, across large numbers of inspection teams, assessors, and organisations, will be a formidable challenge as other inspection and review bodies have found in the past.

The commission will report to the organisations it reviews on the results of those reviews, as well as to the NHS Executive and, in formal terms, directly to the Secretary of State for Health. Responsibility for taking forward its recommendations will rest with those organisations, not the commission; and, as has already been noted, it will have little power to require organisations to implement its recommendations.

\section{Costs and benefits of inspection}

The costs of establishing and running the Commission for Health Improvement will be significant, but are difficult to estimate until more is known about the way it will approach its remit. Visiting each NHS trust every three or four years means between 125 and 160 such reviews to undertake each year, each involving much preparation and follow up. Monitoring the implementation of national guidance and supporting external inquiries will add to the overall bill. A conservative estimate of the total cost might be between $£ 5 \mathrm{~m}$ and $£ 15 \mathrm{~m}$ each year. Initially, the costs of the commission will be met by central government, but the Health Act provides for the commission to recharge the organisations it inspects for some or all of those costs in future. Although the former arrangement has the virtue of simplicity, it might be argued that it leaves the commission overly dependent on the Department of Health. It may be healthier for its independence of mind for the commission to derive most of its income from NHS trusts directly. Because they would be paying for commission reviews, NHS trusts would then be more likely to demand high standards in the review process and perhaps to make use of the results afterwards. The costs would still be modest in comparison to trust annual incomes-ranging, in line with the total cost estimates above, from $£ 10000$ to $£ 30000$ for each trust each year on average.

Of course, there will also be costs arising from the commission's work which fall directly on NHS trusts, although they may not be explicitly identified. Firstly, there will be preparation costs-work involved in collecting information before a commission visit, etc. Experience with accreditation both in the UK and elsewhere suggests that this can be a substantial workload, and some organisations designate somebody to coordinate this full time. Secondly, there will be compliance costs - the cost of making changes to implement recommendations or proposals arising from the commission's report. Potentially, these compliance costs could be much greater than the costs of the process itself, and it is not clear where responsibility for meeting such compliance costs will lie.

Any discussion of the costs of the commission, both direct and indirect, has to be set against some kind of analysis of its impact and benefits. Although it is recognised that measuring the impact of its work will be difficult, we should expect to see the commission show that it adds value to the NHS, by delivering benefits which are worth the costs involved. Rigorous and pragmatic evaluation has an important part to play in assessing the commission's performance and helping to shape and refine its approach to its work.

\section{Publication and dissemination of commission findings}

The government has already made it clear that the results of the Commission for Health Improvement's reviews of healthcare providers will be made public, at least in summary form. ${ }^{4}$ 
The purpose of publication is not really to inform patient choice because most patients have relatively little real choice about which healthcare provider they use. Rather, it is intended to bring public and political awareness and expectations to bear more directly upon healthcare organisations, and to use these powerful forces to promote the uptake of commission recommendations and resulting improvements in health care. It could also be an opportunity for the commission to share examples of good practice and to promote benchmarking and the transfer of learning between healthcare organisations.

Some would argue that the commission's work should remain confidential because it is difficult to conduct honest and open appraisals of organisational performance when the results may be seized upon by the media and misunderstood by the public. The threat of public humiliation for poor performance is likely to engender a defensive and self justifying response from healthcare organisations which makes improvement more difficult to achieve. Moreover, securing the degree of clinical participation and support that the process requires may be made more difficult too. In a tax funded healthcare system, however, these are not sufficient grounds for withholding information about the quality of healthcare from the public, when the public have funded the healthcare organisations concerned and funded the activities of the commission as well. Rather than seeking to prevent or limit publication, we should be looking for ways to make the data published more robust, less liable to misinterpretation, and more accessible. The NHS needs to move beyond its current rather fearful view of public reaction and develop a mature relationship with the media and the public in which the publication of such data is more commonplace and the information is better understood. Anxieties about the prospect of disclosure and publication shown by some healthcare organisations and health professionals may in any case be out of proportion to the reality of public reaction. As the recent publication of performance indicators for healthcare organisations in the NHS, including some comparative mortality and morbidity statistics, ${ }^{8}$ has shown, even quite complex sets of data can be made public without major problems ensuing, although the process is still uncomfortable for those whose data marks them out as outliers.

\section{Conclusions}

The government's quality reforms, and the establishment of the new Commission for Health Improvement, have won widespread support both within the NHS and among the wider public, and the new commission could provide a valuable focus for leadership in healthcare quality improvement in England and Wales.

However, as this article shows, there are some important tensions and dilemmas which the commission will need to acknowledge and work to resolve, if it is to show that it really adds value and brings improvement to the NHS. It is especially important that the commission takes an evidence-based approach to its work, learning the lessons of other inspection and review bodies in the NHS and elsewhere, and maintaining high standards of rigour and objectivity in what it does. The commission is a long term undertaking, and it is more important that the direction of development is properly established and the foundations for its review process are carefully laid than that it should begin to deliver results as soon as possible.

This paper draws on discussions at a special meeting of the Forum on Quality in Health Care at the Royal Society of Medicine in June 1999 which was attended by representatives of many organisations with an interest in quality in health care, and the contribution of participants is gratefully acknowledged. Particular thanks to Jonathan Boyce, Chris Ham, Gill Harvey, Tim Jones, Ror Jones, Roger Mason, Fiona Moss, Peter Spurgeon, Charles
Shaw, John Step, Anthony Townsend, and Peter Wilcock for their helpful comments on earlier drafts.

1 Scrivens E. Accreditation: protecting the professional or the consumer? Buckingham: Open University Press, 1995.

1(a) Brennan TA. The role of regulation in quality improvement. Millbank Quarterly 1998;76:709-31.

2 Power M. The audit society: rituals of verification. Oxford: Oxford University Press, 1997.

3 Department of Health. The new NHS: modern, dependable. London: The Stationery Office, 1997.

4 Department of Health. A first class service: quality in the new NHS. London: DoH, 1998

5 Whitty P. The national health service in England considers the government's plans to improve quality of health care. Quality in Health Care 1998;7:227-32.

6 Department of Health. HSC 1999/33. A first class service: quality in the new NHS: feedback on consultations. London: DoH, 1999.

7 Berwick DM. Continuous improvement as an ideal in health care. New Engl f Med 1989;320:53-6.

8 Department of Health. HSC 1999/139. Improving quality and performance in the new NHS: clinical indicators and high level performance indicators. London: DoH, 1999.

9 Scally G, Donaldson LJ. Clinical governance and the drive for quality improvement in the new NHS in England. BMF 1998;317:61-5.

10 Buetow SA, Roland M. Clinical governance: bridging the gap between managerial and clinical approaches to quality of care. Quality in Health Care 1999;8:ADD PAGE NO.

11 Smith R. All changed, changed utterly. British medicine will be transformed by the Bristol case [editorial]. BMF 1998;316:1917-8

12 Anonymous. An end to secrecy: new medical ethic needed. Guardian, 23 November 1998:17.

13 Merrison A. Report of the royal commission on the national health service. London: HMSO, 1979.

14 Ham C. The third way in health care reform: does the emperor have any clothes? fournal of Health Services Research and Policy 1999;4:168-73.

15 Ham C. Management and competition in the NHS. Second edition. Oxford: Radcliffe Medical Press, 1997. 